\title{
Effect of daily light integral treatments on free amino acids and sugars contributing flavor and acrylamide formation in potato tubers of Solanum tuberosum L.
}

\author{
Minna K. Rotola-Pukkila ${ }^{1,3}$, Anna-Liisa Välimaa ${ }^{2}$, Jukka-Pekka Suomela ${ }^{3}$, Baoru Yang ${ }^{3}$, Saila Karhu ${ }^{4}$ and Anu I. Hopia ${ }^{1}$ \\ ${ }^{1}$ University of Turku, Functional Foods Forum, Faculty of Medicine, FI-20014 Turku, Finland \\ ${ }^{2}$ Natural Resources Institute Finland (Luke), Production Systems, Paavo Havaksen tie 3, Fl-90570 Oulu, Finland \\ ${ }^{3}$ University of Turku, Department of Life Technologies, Food Chemistry and Food Development, FI-20014 Turku, Finland \\ ${ }^{4}$ Natural Resources Institute Finland (Luke), Production Systems, Itäinen Pitkäkatu 4 A, Fl-20520 Turku, Finland \\ e-mail: minna.rotola-pukkila@utu.fi
}

\begin{abstract}
To study the effect of photoperiodic conditions on the chemical composition of potato tubers, seven cultivars, grown under controlled conditions, were evaluated for the content of free amino acids (FAA) and sugars. The differences in these compounds may have an effect on the susceptibility of acrylamide formation during potato processing as well as on the flavor profile of potato products. Tubers were produced in growth chambers under two artificially induced photoperiods; $8 \mathrm{~h}$ light and $15 \mathrm{~h}$ light per day, resulting in conditions with two different daily light integral (DLI) levels. The photoperiodic treatments influenced the total FAA and free sugar contents and composition. Of the analyzed 19 FAAs, the concentrations of 14 FAAs were significantly lower in tubers exposed to the $15 \mathrm{~h}$ light period compared to $8 \mathrm{~h}$ light, whereas the glucose content was significantly higher. The total FAA concentrations were $15-46 \%$ lower and the glucose concentrations 6-64\% higher in the seven cultivars exposed to the $15 \mathrm{~h}$ light conditions than in those grown in $8 \mathrm{~h}$ light.
\end{abstract}

Key words: umami, glutamic acid, reducing sugars, day length

\section{Introduction}

The potato (Solanum tuberosum L.) is cultivated all over the globe, including in high latitude zones, such as northern parts of Europe, Asia and America. Finland is among the northernmost potato production areas in the world. The European boreal region features unique growing conditions for plants: while the growing season remains rather short, nights are short and days are long during that time. Many plants can sense the length of nights by their photoreceptor proteins and according to developmental responses, they can be divided into short day (SD) or long day (LD) plants. In SD plants, special developmental responses require or are promoted by long nights (ca. $12 \mathrm{~h}$ or longer), whereas in LD plants those responses require or favor nights shorter than that (Jackson 2009).

Potato tuberization is promoted by long nights, in other words SD photoperiods, and also favored by moderate growing temperatures (optimum $15-20^{\circ} \mathrm{C}$ ), humid climatic conditions and low rates of nitrogen fertilization (Ewing and Wareing 1978, Krauss 1985, Abelenda et al. 2014, Rosen et al. 2018). Potato varieties cultivated in Europe and North America (Solanum tuberosum spp. tuberosum) are derived from Chilean landraces. However, because of plant breeding, the formation of tubers by these modern commercially grown potato genotypes can be relatively neutral to the photoperiod (Ewing and Wareing 1978, Abelenda et al. 2014). In addition to tuberization, the photoperiod, interacting with light intensity and quality as well as temperature, may substantially affect the biosynthesis and partitioning of primary and secondary metabolites in potato plants, as shown, for example, for starch and phenolic compounds (Stutte et al. 1996, Rubio-Covarrubias et al. 2006).

Raw potato tubers contain flavor precursors, such as carbohydrates, amino acids, ribonucleotides and lipids, the levels of which are affected by plant genotype, growth environment and storage conditions (Jansky 2010). The actual flavor of potatoes is formed from the precursors through enzymatic and chemical reactions during the cooking processes (Solms and Wyler 1979, Jansky 2010). It has been suggested that the taste of cooked potato is largely due to the presence of umami compounds (Solms and Wyler 1979, Morris et al. 2007), though sugars are also considered to contribute directly or indirectly to flavor (Jansky 2010). In the formation of the potato umami taste, the importance of free amino acid glutamic acid in the form of monosodium glutamate (MSG) and, to a lesser extent, aspartic acid has been emphasized (Solms and Wyler 1979, Halpern 2000, Morris et al. 2007). 
In addition to taste, the aroma of cooked and processed potatoes is also formed by the thermal degradation of sugars and lipids and from sugar-amino acid interactions as a part of the Maillard reaction (Ulrich et al. 2000). One fact known for a long time has been the effect of amino acids on potato flavor in the form of an aroma compound methional, which is described to give a cooked potato its aroma (Oruna-Concha et al. 2001). It originates from the thermal degradation of the sulfur-containing amino acid methionine (Ulrich et al. 2000).

Sugars and free amino acids are also reported to have specific undesirable effects on potato quality. The most important of these is the potential to form a probable carcinogen acrylamide, found in potato products processed at elevated temperatures (Rosen et al. 2018). The predominant route for forming acrylamide is a reaction between two primary precursors, a free amino acid (asparagine) and reducing sugars (fructose and glucose), during thermal processing (Halford et al. 2012, Rosen et al. 2018). In fact, acrylamide is formed by the same set of Maillard reactions between free amino acids and reducing sugars, which imparts the browning color for fried, roasted and baked products and affects the formation of aroma and flavor compounds (Halford et al. 2012). Concerning the consumer quality of potatoes, the more recent hypothesis about the role of tyrosine as part of the potato egumi taste is also interesting. It has been suggested that the metabolites of free amino acid tyrosine might be responsible for the unpleasant bitter and astringent egumi taste recognized in potatoes (Sato et al. 2019).

Most of the potato cultivars grown in Finland have been bred in Central Europe, where potato production conditions, including the length of day, differ from those in Finland. The influence of contrasting day length conditions is an important factor for potato production at high latitudes of Europe. Because winter production is not possible in Finland due to limiting temperature and frost conditions, potato growing in Finland is possible in summer LD conditions only. The high quality of products is necessary, because potato is one of the basic foodstuffs of the country and the 4th largest article of food plant production (FAO 2021). However, the literature published on the possible differences in potato quality due to shorter and longer days is relatively scarce. In this research, we study the effects of high latitude light conditions during the growing season on the quality of potato tubers. Thus, the influence of two photoperiodic treatments on the concentration of free sugars and free amino acids (FAAs) in seven potato cultivars were studied. The response was examined using the treatments of $8 \mathrm{~h}$ light (SD) and $15 \mathrm{~h}$ light (LD) per day in controlled growth chambers, consequently exposing plants to two different daily light integrals, or DLIs (rates of photosynthetically active radiation), and differing daily mean temperatures. The concentration of sugars and FAAs analyzed were considered as flavor precursors or taste enhancers as well as potential acrylamide precursors.

\section{Materials and methods}

\section{Plant material}

For this research, seven potato cultivars commercially available in Finland were used: 'Jazzy', 'Rock', 'Jussi', 'Gala', 'Soraya', 'Jessica' and 'Annabelle'. Cultivar Jussi has been bred in Finland, while the other six have been developed by Central European potato breeders. The tubers were obtained from Finnish seed potato companies. The studies were carried out under laboratory conditions. A total of 20 to 27 tubers of similar size of each cultivar were sprouted under continuous light at room temperature until the sprouts were at least $2 \mathrm{~mm}$ long. Sprouting time varied between 1 to 23 days, due to the different physiological ages of the tubers of different cultivars, since their growing was started at different times during the year (Table 1). The tubers were planted in pots with a growing medium of Sphagnum peat:sand $\operatorname{mix}(2: 1)$, and to ensure sufficient root aeriation, a layer of lightweight expanded clay aggregates (LECA) was placed at the bottom of the pots. The plants were regularly fertigated with a complete fertilizer (Puutarhan KESÄ, GreenCare, Berner, Finland), and due to the rather modest harvest of the first growing set of cultivars ('Jazzy', 'Rock'), nitrogen base fertilizer (YaraTera Krista U (N 46.2), Yara International ASA, Norway) was applied to the growing medium of the other cultivars.

The tubers were grown in controlled growth chambers: 'Jazzy', 'Rock', 'Jussi', 'Gala', and 'Soraya' (10 pots of 6 liters per cultivar per treatment) in a Fitotron SGC 120 chamber (LaboTest, Sweden) at Natural Resources Institute Finland (Luke) Oulu, and 'Jessica' and 'Annabelle' (9 pots of 13 liters per cultivar per treatment) in a PGW36 chamber (Conviron Ltd., Canada) in the Biosphere laboratory in Joensuu (Luke and University of Eastern Finland, Joensuu). The details of the experimental setup of the cultivars are described in Table 1. Photoperiods were adjusted to SD conditions ( $8 \mathrm{~h}$ light, $16 \mathrm{~h}$ dark) and LD conditions ( $15 \mathrm{~h}$ light, $9 \mathrm{~h}$ dark). The tubers were grown until senescence growth state determined according to Hack et al. (1993). At harvest, the tubers of each cultivar in the same treatment were combined into one biological sample and stored in the dark in paper bags at $+4 \pm 1^{\circ} \mathrm{C}$. The maximum 
storage time was one month and was always the same for all tubers of the same cultivar. For chemical analysis, the tubers were lyophilized within 10 days of arrival at the analysis laboratory.

Table 1. Sprouting and growing times and details of the experimental set-up of the cultivars. Temperatures were adjusted to $20{ }^{\circ} \mathrm{C}$ for the light period and $14{ }^{\circ} \mathrm{C}$ for the dark period, and air humidity was adjusted to $60 \%$.

\begin{tabular}{|c|c|c|c|c|c|c|c|}
\hline Cultivar & Jazzy & Rock & Jussi & Gala & Soraya & Jessica & Annabelle \\
\hline Growing chamber & SGC 120 & SGC 120 & SGC 120 & SGC 120 & SGC 120 & PGW36 & PGW36 \\
\hline Pots (n) and volume (I) & $10(6 \mathrm{l})$ & $10(6 \mathrm{l})$ & $10(6 \mathrm{l})$ & $10(6 \mathrm{l})$ & $10(6 \mathrm{I})$ & $9(13 \mid)$ & 9 (13I) \\
\hline Plants per pot (n) & 1 & 1 & 2 & 2 & 2 & 3 & 3 \\
\hline Sprouting time, days & 23 & 23 & 1 & 2 & 2 & 22 & 22 \\
\hline Growing time, days & 91 & 91 & 93 & 113 & 113 & 114 & 114 \\
\hline Growing season & $\begin{array}{c}\text { Nov 2016- } \\
\text { Feb } 2017\end{array}$ & $\begin{array}{c}\text { Nov 2016- } \\
\text { Feb } 2017\end{array}$ & $\begin{array}{l}\text { March 2017- } \\
\text { June } 2017\end{array}$ & $\begin{array}{c}\text { Sep 2017- } \\
\text { Jan } 2018\end{array}$ & $\begin{array}{c}\text { Sep 2017- } \\
\text { Jan } 2018\end{array}$ & $\begin{array}{l}\text { Nov 2017- } \\
\text { March } 2018\end{array}$ & $\begin{array}{l}\text { Nov 2017- } \\
\text { March } 2018\end{array}$ \\
\hline DLI SD $\left(\mathrm{mol} \mathrm{m}^{-2} \mathrm{~d}^{-1}\right)$ & 3.9 & 3.9 & 3.9 & 3.9 & 3.9 & 4.0 & 4.0 \\
\hline DLI LD $\left(\mathrm{mol} \mathrm{m}^{-2} \mathrm{~d}^{-1}\right)$ & 7.3 & 7.3 & 7.3 & 7.3 & 7.3 & 7.6 & 7.6 \\
\hline \multicolumn{8}{|l|}{ Chemical analysis: } \\
\hline Experiment & 1 & 1 & 1 & 2 & 2 & 2 & 2 \\
\hline Analysis time & fall 2017 & fall 2017 & fall 2017 & fall 2018 & fall 2018 & fall 2018 & fall 2018 \\
\hline
\end{tabular}

\section{Pretreatment of potato tubers}

Four tubers of similar size of every cultivar and from both treatments (SD and LD) were chosen for chemical analysis. The total weight of the four tubers was 53-67 g. Fresh, cleaned tubers were sliced to the thickness of 0.3 $\mathrm{cm}$ and divided into three replicates and frozen at $-40{ }^{\circ} \mathrm{C}$ before freeze drying for $30 \mathrm{~h}$ in a vacuum at $-40{ }^{\circ} \mathrm{C}$. To obtain dry matter content, the slices were weighed before and after freeze-drying. The dried slices were stored in a freezer $\left(-20^{\circ} \mathrm{C}\right)$ before analysis.

\section{Solvents and reagents}

Chemicals and solvents were of HPLC or analytical grade. A certified reference material, the solution containing 17 amino acids in $0.1 \mathrm{M} \mathrm{HCl}$ and the solid standard amino acids and sugars $\beta$-alanine, L-citrulline, L-ornitihine monohydrochloride, taurine, gamma-aminobutyric acid (GABA), D-fructose, xylitol and tartaric acid were acquired from Sigma Alrich (St. Louis, Missouri, USA). L-asparagine monohydrate, L-glutamine, L-tryptophan and L-theanine were purchased from Wako Pure Chemical Industries, Ltd. (Osaka, Japan), D-glucose and sucrose from VWR Chemicals (BDH Prolabo, Leuven Belgium) and Tri-Sil HTP Reagent was obtained from Thermo Scientific.

Methanol (MeOH), acetonitrile ( $\mathrm{ACN}$ ), hydrochloric acid (35\%), potassium dihydrogen phosphate, dipotassium hydrogen phosphate, sodium phosphate monobasic and 3-mercaptopropionic acid (3-MPA) were purchased from Sigma-Aldrich Chemie GmbH (Steinheim, Germany) and VWR Chemicals (Radnor, Pennsylvania, USA). Boric acid was purchased from Merck KGaA (Darmstadt, Germany) and sodium hydroxide from VWR Chemicals (BDH Prolabo, Leuven Belgium). Derivatization reagent o-phthalaldehyde (OPA, $\geq 98 \%$ ) and 85\% ortophosphoric acid (8590\%) were acquired from MP Biomedicals (Santa Ana, California, USA). Ethanol anhydride was acquired from Yliopiston Apteekki (Helsinki, Finland).

\section{Extraction of sugars and amino acids}

Extraction was based on a previously reported procedure employed by Ranogajec et al. (2010) and Rotola-Pukkila et al. (2015), with slight modifications. An identical hot water extraction method was used for both sugars and FAAs. The extracts were stored at $-20^{\circ} \mathrm{C}$ if not analyzed immediately. 


\section{Chromatographic analysis}

The cultivars of potatoes were analyzed chromatographically by HPLC and GC to determine their free sugar and FAA concentrations. The analysis of potato tubers was done in two batches, from now on referred to as Experiments 1 and 2 (Table 1).

The sugar and FAA compositions of cultivars Jazzy, Rock and Jussi (Experiment 1) were analyzed by liquid chromatographic methods, whereas the FAAs of the cultivars Gala, Soraya, Jessica and Annabelle (Experiment 2) were analyzed by liquid chromatographic and sugars by gas chromatographic method. Both treatments of each cultivar were analyzed in triplicate. For liquid chromatography analysis, calibration curves of external standards were constructed by analysis of reference compounds of varying concentrations and applied in quantification of analytes. For gas chromatography analysis, correction factors were determined by analysis of authentic reference compounds (internal standards) and applied in the quantification of analytes. Data on the three most common sugars, sucrose, glucose and fructose, were obtained from potato extracts, together with 19 free amino acids.

\section{Analysis of free sugars and starch}

In Experiment 1, the sugar concentrations were determined according to Kontukoski et al. (2015) and in the Experiment 2 the method employed by Zheng et al. (2009). Trimethylsilane (TMS) derivatives of the samples were analyzed using the gas chromatography (GC) technique with a Shimadzu GC-2010Plus equipped with a flame ionization detector (FID) (Shimadzu Corporation, Kyoto, Japan). Xylitol and tartaric acid were used as internal standards. The concentration of starch was analyzed by the method used by Järvi et al. (1998). The starch content of fresh potatoes correlates with potato density. Thus, specific gravity of fresh tubers was measured by weighing washed potato tubers first in air, and then weighting immersed in clean water of $17.5^{\circ} \mathrm{C}$.

\section{Analysis of free amino acids}

In Experiment 1, amino acids were identified using the UHPLC method described in the technical notes provided by Shimadzu (Shimadzu Corporation). FAA analysis was performed using a Kinetex C18 column (100×4.6 mm, $2.6 \mu \mathrm{m}$, Phenomenex) and a Security Guard ULTRA cartridge UHPLC C18 pre-column (Phenomenex) on a Shimadzu Nexera X2 UHPLC instrument equipped with a RF-20AXS fluorescence detector. The solvents used in the gradient program were A: $20 \mathrm{mM}$ phosphate buffer $\left(\mathrm{pH} \mathrm{6.5)}\right.$ and B: 45/40/15 ACN/MetOH/ $\mathrm{H}_{2} \mathrm{O}$. The flow rate was set to $1.0 \mathrm{ml} \mathrm{min}^{-1}$ and the column temperature was maintained at $35^{\circ} \mathrm{C}$. Amino acids were derivatized on-line automatically with 3-MPA/OPA. Fluorescence detection was set at a wavelength of $340 \mathrm{~nm}$ for excitation and $450 \mathrm{~nm}$ for emission.

In Experiment 2, amino acids were analyzed and identified according to the Eclipse AAA protocol described in Technical Note 5980-1193 (Agilent Technologies). The separation was performed using a Zorbax Eclipse AAA column (Rapid Resolution $4.6 \times 150 \mathrm{~mm}, 3.5 \mu \mathrm{m}$, Agilent) equipped with a guard column (4.6 × $12.5 \mathrm{~mm}, 5 \mu \mathrm{m}$, Agilent). A Shimadzu HPLC equipped with a RF-20AXS fluorescence detector was used to confirm the FAAs from 3-MPA/ OPA derivatized supernatants. Fluorescence detection was set at wavelengths of $340 \mathrm{~nm}$ for excitation and 450 $\mathrm{nm}$ for emission. The column temperature was kept at $40^{\circ} \mathrm{C}$, and the solvents used in the gradient program were A: $40 \mathrm{mM} \mathrm{NaH}_{2} \mathrm{PO}_{4}, \mathrm{pH}$ adjusted to 7.8 with $\mathrm{NaOH}$ and B: 45/45/10 ACN/MetOH/H $\mathrm{H}_{2} \mathrm{O}$.

\section{Statistical analysis}

The statistical analysis of data was performed using IBM SPSS Statistics Version 26.0 (IBM Corporation, Armonk, NY). Comparison of the means of the two treatments (SD and LD) for every sugar and amino acid were carried out by paired T-test with a $5 \%$ significance level by using different cultivars as replicates. The equality of variances was assessed by Levene's test.

A principal component analysis (PCA) was performed with The Unscrambler X 10.3 (64-bit) to evaluate the dependence of the experimental results and to determine correlations between the photoperiodic treatments and the analyzed chemical properties. All data were presented as a mean \pm standard deviation (SD). Three technical replicates of seven different cultivars per treatment $(8 \mathrm{~h}$ and $15 \mathrm{~h}$ ) were used for the statistical analysis. Altogether $3 \times 7=21$ analyses per data point were used. 


\section{Results \\ Sugar and FAA concentration in seven cultivars}

The concentrations of total free sugars in the cultivars studied varied between 1330 and $2164 \mathrm{mg} 100 \mathrm{~g} \mathrm{~g}^{-1}$ in SD and

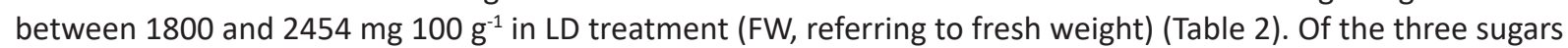
analyzed, glucose was the most abundant in all cultivars, accounting for $57-65 \%$ of the total sugar content. The highest values were in the cultivar Soraya.

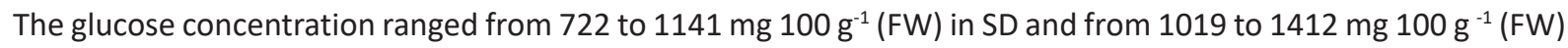
in LD tubers. Those tubers exposed to longer light period (LD) thus had, depending on the cultivar, 6-64\% higher glucose concentrations than those tubers grown in SD. Concentrations of fructose varied similarly but were generally lower than those of glucose, representing $28-46 \%$ of the total sugars. The sucrose content was the lowest among the three sugars in all samples, representing only $0-18 \%$ of the sum of sugars. The concentration of starch (6.4-11.7\%), as well as tuber fresh weight or dry weight harvest (12.2-18.5\%), was not affected by the treatments (data not shown).

Table 2. Free sugar concentrations (mean \pm standard deviation of three technical replicates) of potato tubers as $\mathrm{mg}^{100} \mathrm{~g}^{-1}$ fresh weight as a result of short day (SD) and long day (LD) treatments.

\begin{tabular}{|c|c|c|c|c|c|c|c|c|}
\hline \multirow{2}{*}{$\begin{array}{l}\text { Cultivar } \\
\text { Treatment }\end{array}$} & \multicolumn{2}{|c|}{ Jazzy } & \multicolumn{2}{|c|}{ Rock } & \multicolumn{2}{|c|}{ Jussi } & & \\
\hline & SD & LD & SD & LD & SD & LD & & \\
\hline Sucrose & $78 \pm 6$ & $65 \pm 6$ & $124 \pm 8$ & $118 \pm 4$ & $0 \pm 0$ & $0 \pm 0$ & & \\
\hline Glucose & $908 \pm 39$ & $1412 \pm 18$ & $1067 \pm 56$ & $1134 \pm 36$ & $722 \pm 10$ & $1186 \pm 9$ & & \\
\hline Fructose & $703 \pm 64$ & $821 \pm 36$ & $750 \pm 53$ & $554 \pm 89$ & $609 \pm 7$ & $636 \pm 25$ & & \\
\hline Total sugars & 1688 & 2298 & 1941 & 1806 & 1330 & 1821 & & \\
\hline Cultivar & \multicolumn{2}{|c|}{ Gala } & \multicolumn{2}{|c|}{ Soraya } & \multicolumn{2}{|c|}{ Jessica } & \multicolumn{2}{|c|}{ Annabelle } \\
\hline Treatment & SD & LD & SD & LD & SD & LD & SD & LD \\
\hline Sucrose & $203 \pm 2$ & $246 \pm 5$ & $225 \pm 1$ & $399 \pm 4$ & $151 \pm 5$ & $184 \pm 8$ & $73 \pm 1$ & $168 \pm 3$ \\
\hline Glucose & $893 \pm 9$ & $1019 \pm 19$ & $1141 \pm 4$ & $1345 \pm 11$ & $1105 \pm 3$ & $1264 \pm 18$ & $927 \pm 14$ & $1123 \pm 6$ \\
\hline Fructose & $601 \pm 10$ & $626 \pm 7$ & $798 \pm 10$ & $710 \pm 5$ & $622 \pm 9$ & $695 \pm 9$ & $551 \pm 9$ & $509 \pm 2$ \\
\hline Total sugars & 1697 & 1891 & 2164 & 2454 & 1878 & 2143 & 1551 & 1800 \\
\hline
\end{tabular}

The concentrations of 18 proteinogenic and one non-proteinogenic amino acid (GABA) formed the total FAA content of the tubers in our research. Six FAAs and the total content of all analyzed FAAs are presented in Table 3. The selected FAAs are predominant in potatoes (asparagine and glutamine), involved in possible acrylamide formation (asparagine) or found to be potato flavor precursors (glutamic acid, aspartic acid, methionine and tyrosine), as described in the introduction. The sum of FAAs in the studied cultivars ranged from 484 to 763 in LD and from

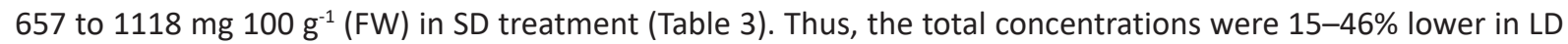
tubers than in SD tubers within the same cultivar. The predominant amino acids in the tubers were asparagine, glutamine, arginine, aspartic acid, glutamic acid, GABA, lysine and valine with some cultivar-dependent variations in the proportion of these amino acids to the total FAA. In all seven cultivars studied, asparagine was the most abundant and glutamine the second-most abundant free amino acid, comprising $28-40 \%(w / w)$ and $11-30 \%(w / w)$ of the total free amino acid pool, respectively. The analyzed free asparagine concentrations were between 202

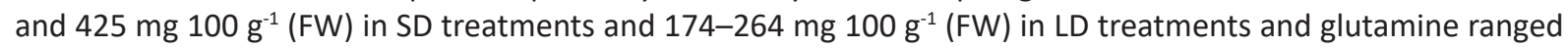
from 153-308 and 58 to 191 and mg $100 \mathrm{~g}^{-1}$ (FW), respectively. Thus, LD treatment resulted in a 6-51\% lower concentration of asparagine and a 31-63\% lower concentration of glutamine as compared to SD treatment (Table 3).

The sum of the umami-taste-enhancing amino acids, glutamic acid and aspartic acid, constituted 5-15\% (w/w) of the total FAA pool. In the studied potato cultivars, the glutamic acid concentration was $13-55 \%$ lower in LD tubers compared to SD tubers. In contrast, aspartic acid content was higher in LD tubers than in SD tubers in six out of the seven analyzed cultivars. Further, in the case of methionine, the precursor of the potato aroma methional, an 11-58\% lower content was measured in LD tubers than in SD tubers. The potential egumi taste precursor tyrosine had a lower concentration in LD tubers than in SD tubers in five out of the seven cultivars. 
Table 3. Free amino acid concentrations (mean \pm standard deviation of three technical replicates) of potato tubers as $\mathrm{mg} 100 \mathrm{~g}^{-1}$ fresh weight as a result of short day (SD) and long day (LD) treatments.

\begin{tabular}{|c|c|c|c|c|c|c|c|c|}
\hline \multirow{2}{*}{$\begin{array}{l}\text { Cultivar } \\
\text { Treatment }\end{array}$} & \multicolumn{2}{|c|}{ Jazzy } & \multicolumn{2}{|c|}{ Rock } & \multicolumn{2}{|c|}{ Jussi } & & \\
\hline & SD & LD & SD & LD & SD & LD & & \\
\hline Aspartic acid & $37.9 \pm 1.2$ & $39.1 \pm 0.4$ & $47.1 \pm 1.9$ & $43.4 \pm 3.4$ & $32.7 \pm 0.7$ & $36.4 \pm 0.1$ & & \\
\hline Glutamic acid & $30.3 \pm 0.9$ & $13.7 \pm 0.3$ & $44.8 \pm 1.9$ & $28.7 \pm 2.0$ & $45.3 \pm 0.8$ & $31.5 \pm 0.4$ & & \\
\hline Asparagine & $425 \pm 11$ & $264 \pm 2$ & $202 \pm 7$ & $175 \pm 16$ & $378 \pm 8$ & $241 \pm 1$ & & \\
\hline Glutamine & $243 \pm 7$ & $149 \pm 2$ & $153 \pm 6$ & $100 \pm 9$ & $308 \pm 7$ & $191 \pm 0.4$ & & \\
\hline Methionine & $20.9 \pm 0.6$ & $12.1 \pm 0.2$ & $7.1 \pm 0.2$ & $3.6 \pm 0.2$ & $20.7 \pm 0.4$ & $11.6 \pm 0.1$ & & \\
\hline Tyrosine & $8.3 \pm 0.2$ & $5.7 \pm 0.1$ & $7.7 \pm 0.2$ & $6.5 \pm 0.1$ & $20.7 \pm 0.5$ & $9.7 \pm 0.1$ & & \\
\hline Sum of 19 FAAs & 1062 & 718 & 657 & 484 & 1118 & 727 & & \\
\hline Cultivar & \multicolumn{2}{|c|}{ Gala } & \multicolumn{2}{|c|}{ Soraya } & \multicolumn{2}{|c|}{ Jessica } & \multicolumn{2}{|c|}{ Annabelle } \\
\hline Treatment & SD & LD & SD & LD & SD & LD & SD & LD \\
\hline Aspartic acid & $56.0 \pm 0.5$ & $65.5 \pm 4.6$ & $52.8 \pm 2.7$ & $77.5 \pm 1.7$ & $41.4 \pm 2.3$ & $50.7 \pm 1.2$ & $41.4 \pm 1.0$ & $49.4 \pm 0.8$ \\
\hline Glutamic acid & $31.2 \pm 0.5$ & $26.0 \pm 3.6$ & $28.1 \pm 2.0$ & $22.2 \pm 1.0$ & $34.0 \pm 2.0$ & $27.9 \pm 0.9$ & $26.5 \pm 0.2$ & $22.4 \pm 0.1$ \\
\hline Asparagine & $304 \pm 3$ & $259 \pm 18$ & $263 \pm 15$ & $183 \pm 4$ & $237 \pm 13$ & $223 \pm 6$ & $353 \pm 8$ & $174 \pm 3$ \\
\hline Glutamine & $284 \pm 3$ & $136 \pm 9$ & $215 \pm 12$ & $97.9 \pm 2.3$ & $168 \pm 9$ & $115 \pm 3$ & $157 \pm 3$ & $58.3 \pm 0.5$ \\
\hline Methionine & $9.6 \pm 0.3$ & $8.5 \pm 0.4$ & $12.5 \pm 0.8$ & $7.4 \pm 0.2$ & $12.2 \pm 0.6$ & $9.4 \pm 0.2$ & $13.7 \pm 0.4$ & $7.2 \pm 0.1$ \\
\hline Tyrosine & $9.5 \pm 0.5$ & $16.5 \pm 1.1$ & $17.0 \pm 0.9$ & $17.3 \pm 0.5$ & $17.7 \pm 0.5$ & $13.1 \pm 0.3$ & $20.3 \pm 0.5$ & $11.7 \pm 0.2$ \\
\hline Sum of 19 FAAs & 922 & 763 & 856 & 618 & 735 & 622 & 907 & 496 \\
\hline
\end{tabular}

FAA $=$ free amino acid

\section{Effect of growth conditions on free sugar and FAA composition}

The effect of growth conditions on the concentrations of three sugars and 19 amino acids are presented in Table 4, statistically analyzed by considering the concentration averages of seven cultivars (including three technical replicates of each) as replications. Of the three sugars analyzed, there was a statistically significant difference $(p<0.001)$ in glucose concentrations between the two photoperiodic treatments. The glucose concentration was higher in LD tubers than in SD tubers. Similarly, there was statistically significant difference $(p \leq 0.05)$ between SD and LD growing conditions in 15 out of the 19 analyzed FAAs. The concentrations were lower in LD tubers than in SD tubers except for aspartic acid, which had significantly higher concentration values in the LD tubers (Table 4).

To investigate the possibility of separate groups existing within the cultivars, a principal component analysis (PCA) was performed for the cultivars from each photoperiodic treatment. The analysis included the mean values of the results obtained from the two photoperiodic treatments of the seven cultivars for each of the chemical components analyzed. The components PC1 and PC2 explained 69\% of the variability of analyzed properties (Fig. 1 and 2) with a simultaneous $31 \%$ loss of information.

The scores plot for the PCA analysis indicates that the cultivars are not arranged in a random way. The distinction between SD and LD groups can be seen: the SD treatment of each cultivar is always to the right of the LD results in the direction of PC1, similar treatments correlating positively with each other. This is not clear for all cultivars, but the clearest difference can be seen for 'Jazzy', 'Rock', 'Jussi' and 'Annabelle' (Fig. 1). Within the same treatment, there are also differences between the cultivars. This is most clearly seen between the 'Jazzy' SD and 'Annabelle' SD cultivars, which are located in different directions along the axis PC2. Instead, a clear cluster of similarity is formed for the cultivars Gala, Soraya and Jessica in both the SD and LD samples. In the correlation loadings plot (Fig. 2), asparagine, glutamine, leucine, isoleucine, methionine, valine, histidine and serine are located to the right of the PC1 axis, highly positively correlating with each other. In contrast, sucrose, glucose and aspartic acid are located to the left along the PC1 axis, having a highly negative correlation with most FAAs. The aforementioned compounds explain the differences between the results of the SD and LD treatments due to their location in opposite directions on the PC1 axis, with FAAs near the outer ellipse showing close to $100 \%$ of the explained variance. In contrast, fructose and glutamic acid are located in the inner circle, not illustrating any of the differences in the results of the treatments. 
Table 4. Free sugars and amino acids of potato tubers grown in SD and LD photoperiods. Average of seven potato cultivars (with three technical replicates each), in $\mathrm{mg}^{100 \mathrm{~g}^{-1}}$ (FW).

\begin{tabular}{|c|c|c|c|}
\hline Compound & SD & LD & Treatment \\
\hline & mean $\pm s d$ & mean $\pm s d$ & $p$ value \\
\hline \multicolumn{4}{|l|}{ Sugars } \\
\hline Sucrose & $124 \pm 77$ & $169 \pm 123$ & - \\
\hline Glucose & $973 \pm 140$ & $1212 \pm 131$ & $<0.001$ \\
\hline Fructose & $666 \pm 89$ & $650 \pm 106$ & - \\
\hline FAAs & & & - \\
\hline Alanine & $6.9 \pm 1.9$ & $5.4 \pm 1.0$ & 0.004 \\
\hline Arginine & $61.1 \pm 16.5$ & $38.0 \pm 11.9$ & $<0.001$ \\
\hline Asparagine & $309 \pm 77$ & $217 \pm 38$ & $<0.001$ \\
\hline Aspartic acid & $44.2 \pm 8.0$ & $51.7 \pm 14.2$ & 0.043 \\
\hline GABA & $32.8 \pm 10.4$ & $37.3 \pm 8.7$ & - \\
\hline Glutamic acid & $34.3 \pm 7.4$ & $24.6 \pm 5.7$ & $<0.001$ \\
\hline Glutamine & $218 \pm 60$ & $121 \pm 41$ & $<0.001$ \\
\hline Glycine & $1.7 \pm 0.6$ & $1.1 \pm 0.6$ & 0.002 \\
\hline Histidine & $13.7 \pm 5.1$ & $10.5 \pm 2.8$ & 0.018 \\
\hline Isoleucine & $20.1 \pm 5.8$ & $14.1 \pm 3.9$ & $<0.001$ \\
\hline Leucine & $8.3 \pm 3.3$ & $6.3 \pm 2.7$ & 0.037 \\
\hline Lysine & $26.8 \pm 9.2$ & $18.1 \pm 8.3$ & 0.003 \\
\hline Methionine & $13.8 \pm 5.0$ & $8.5 \pm 2.8$ & $<0.001$ \\
\hline Phenylalanine & $15.0 \pm 12.5$ & $10.2 \pm 7.4$ & - \\
\hline Serine & $15.4 \pm 4.0$ & $11.5 \pm 2.9$ & 0.001 \\
\hline Threonine & $11.1 \pm 2.5$ & $8.6 \pm 1.4$ & $<0.001$ \\
\hline Tryptophan & $7.9 \pm 7.7$ & $7.6 \pm 7.0$ & - \\
\hline Tyrosine & $13.5 \pm 4.8$ & $11.5 \pm 4.3$ & - \\
\hline Valine & $40.1 \pm 8.9$ & $29.4 \pm 7.4$ & $<0.001$ \\
\hline
\end{tabular}

$\mathrm{SD}=$ short day; $\mathrm{LD}=$ long day; $\mathrm{sd}=$ standard deviation

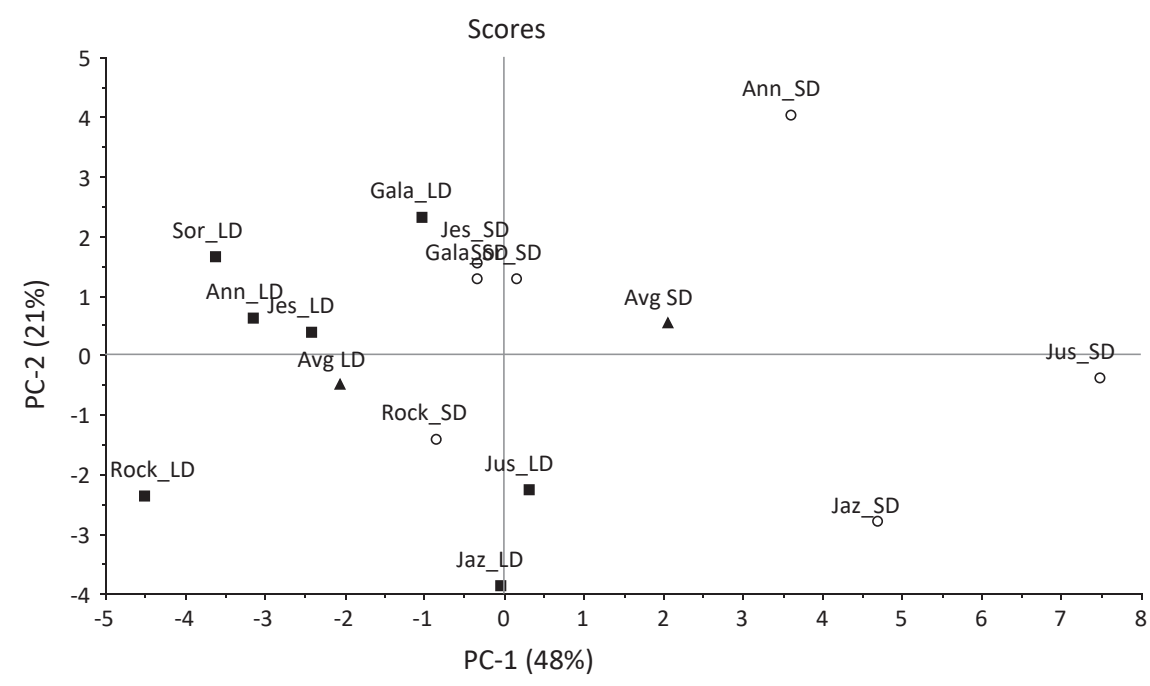

Fig. 1. PCA Scores plot. The SD (" $8 \mathrm{~h}$ ") photoperiod samples are marked by open circles and LD ("15h") photoperiod samples are marked by squares. The averages of all SD (“Avg SD") and LD (“Avg LD") samples are marked by triangles in the figure. 


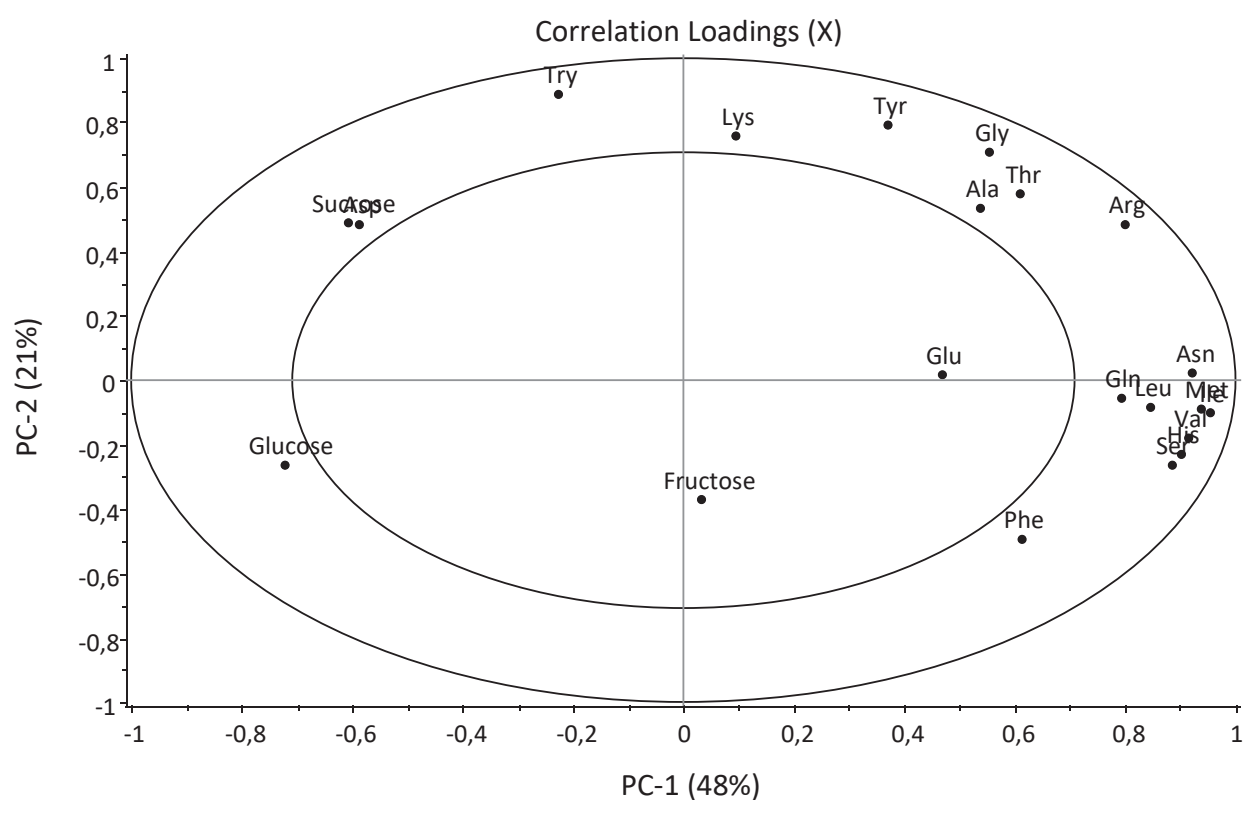

Fig. 2. PCA Correlation Loadings plot. Three sugars and 19 free amino acids are presented as variables.

\section{Discussion}

The analyzed concentrations of sugars and FAAs in tubers of seven cultivars were at the same level as reported in previous studies. Total sugar contents and the concentrations of individual sugars in the studied cultivars were also of the same order of magnitude as previous research results (Becalski et al. 2004, Vivanti et al. 2006, Aisala et al. 2016). As in our study, Aisala et al. (2016) showed that the concentration of glucose was highest of the three most abundant sugars in uncooked potato extracts. The total FAA concentrations in the cultivars were in a similar range to the previous study by Brierley et al. (1997). The predominance of asparagine and glutamine in our study (45-64\% of total FAAs) support the findings of Eppendorfer and Bille (1996) and Elmore et al. (2007), who showed asparagine as typically accounting for at least $30 \%$ of the total concentration of FAAs in fresh potatoes. The proportions of other predominant FAAs in tubers were relatively low due to the high content of asparagine and glutamine. The share of glutamic acid, for example, formed only 1.9-6.8\% of the total FAA pool, being at similar level to that reported by Aisala et al. (2016).

The results of the present study showed clearly that the photoperiodic treatments with different DLIs resulted in differences in the concentration of free amino acids and free sugars in potato tubers. Tubers developed in LD conditions had lower FAA concentrations than tubers grown in an SD photoperiod. This difference was significant in 14 out of the studied 19 amino acids. Only the aspartic acid concentration was higher in LD than SD tubers. In contrast, not all analyzed sugars showed such a clear difference between the two photoperiods. However, the concentration of the most abundant sugar, glucose, was always higher in tubers grown in LD than those grown in SD (Table 4) conditions.

According to several studies (Hårdh and Hårdh 1977, Rosenfeld et al. 1997, Zheng et al. 2009, Steindal Hykkerud et al. 2013), high latitudes and their conditions are associated with variation in the content of some health- and taste-related components in plant crops, when compared to those grown further south. For example, Mølmann et al. (2018) stated that long photosynthetic light periods can influence eating quality attributes in swede roots (Brassica napus), enhancing a sweet and less bitter taste.

Potato tuber development is affected especially by light interception, temperature and day length (Kooman and Haverkort 1995). In our experiment, no significant difference in tuber fresh weight or dry weight harvest, nor in starch concentration, was found between the treatments. While SD is generally known to improve the formation of tubers, their further loading with starch and sugars is dependent on the photosynthetic activity of plants (Moorby 1970). An increased level of the major sugar in potato tubers, glucose, was thus an expected response to LD treatment with higher DLI and daily mean temperature than in SD treatment, when increased photosynthetic metabolism in plants was possible. Long daily light periods with an optimal temperature for photosynthesis provided by the LD treatment may also explain the contradiction of our results to the earlier results of Marwaha and Sandhu 
(2002), who reported that potato cultivars grown in autumn SD conditions displayed a higher concentration of reducing sugars than those grown in spring LD conditions. In their experiment, the potato plants were exposed to beyond-optimum and considerably higher temperatures, up to $41^{\circ} \mathrm{C}$, in spring LD conditions.

Marwaha and Sandhu (2002) also found, contrary to our results, lower concentrations of FAAs in potato tubers grown in autumn SD conditions than in those grown in spring LD conditions. The contrasting results may again be due to high difference in growing temperatures between these two studies. In our study, mean daily temperatures remained low in the SD treatment, due to the long diurnal dark period of only $14^{\circ} \mathrm{C}$, planned to mimic European high-latitude conditions. Even light-quality dependent differences in primary and secondary metabolite profiles in the tubers of potato cultivars have been reported (Paradiso et al. 2019), which may explain the differences in the results of different studies.

When assessing the practical relevance of the results, the differences due to different growth conditions can be both desirable and undesirable. Amino acids and sugars affect potato quality in multiple ways. For example, the increase in concentration would be favorable for flavor in the case of umami compounds or sweet flavor compounds. On the other hand, a higher amino acid content can increase the unpleasant bitter taste or the possibility of the formation of harmful acrylamide in the presence of sugars.

Our results showed that compared to LD tubers, SD tubers had a higher amount of umami amino acid glutamic acid and the aroma precursor methionine, which are considered to affect potato flavor positively, However, SD tubers also had higher level of the bitter FAAs arginine, valine and isoleucine, and a lower level of aspartic acid, which is also an umami amino acid (Kirimura et al. 1969). Tyrosine, the potential source of egumi, did not show a consistent difference between the two growth conditions. Higher sugar levels under LD conditions indicate the possibility of their giving rise to sweetness in these tubers.

It is important to remember that the concentrations of the individual compounds alone do not explain the flavor. For example, in the case of umami flavor formation, the interaction of both the umami amino acids, glutamic and aspartic acid, with 5'-ribonucleotides results in a synergistic increase of umami flavor intensity (Solms and Wyler 1979, Morris et al. 2007, Jansky 2010). Numerous volatile compounds and their mutual proportion with nonvolatiles in the product also influence the sensory quality of food. In addition to chemical measurements and analytical sensory profiles, hedonic preference tests should also be considered (Aisala et al. 2020).

Considerable research has been carried out to uncover the factors influencing acrylamide formation in food raw materials. In the recent review article by Rosen et al. (2018), it was stated that acrylamide precursors, asparagine and reducing sugars, correlated largely with the acrylamide forming potential. As asparagine and glucose are both known to be the major acrylamide precursors, their concentration in raw potato tubers might have a notable effect on acrylamide formation in processed potato products. In our study, the concentration of glucose was increased by LD conditions. The amount of asparagine was, however, lower in LD tuber than in SD tubers. We thus need end-point determinations such as acrylamide analysis as well as sensory analyses to definitively judge the role of day length and growing conditions on potato quality.

\section{Conclusions}

The results of our study indicated that the two day-length conditions studied led to differences in the measured metabolite content and composition in potato tubers. The tubers grown in long day conditions displayed a higher concentration of glucose, whereas free amino acid concentrations were higher in tubers grown in short day conditions. In terms of flavor, long day conditions may produce more sugar-induced sweetness in the tubers and increase the sensation of savory umami taste due to the umami amino acid aspartic acid. On the other hand, short day conditions may increase the sensation of umami and cooked potato aroma in the processed potato products due to increased levels of the amino acids glutamic acid and methional, respectively. Acrylamide is one of the major health concerns in processed potato products. According to current knowledge, it needs both asparagine and reducing sugars, glucose and fructose to form. Based on this study, the development of these precursor compounds had opposing trends under long- and short-day conditions. Whether one of the compounds reacting may be limiting to acrylamide formation requires further research. The study also suggests that the potato genotype can influence how it responds to ambient growth conditions. 


\section{Acknowledgements}

This article is dedicated to the memory of Senior Researcher Elina Virtanen, Natural Resources Institute Finland (Luke), for her enthusiasm in science that produced the ideas and realization of this study. Our sincere thanks go to Mrs. Anne-Maria-Möttönen, Mr. Matti Savinainen, and Mr. Raino Lievonen, Natural Resources Institute Finland (Luke), for their technical assistance. Dr. Titta Kotilainen, Natural Resources Institute Finland (Luke), is acknowledged for reviewing the manuscript. Oskar Laaksonen, University of Turku, is acknowledged for help with statistical analysis. This work was supported by the project A72073 Better Potato from North funded by the Council of Oulu Region from the European Regional Development Fund (ERDF) of the European Union. Minna Rotola-Pukkila acknowledges funding from the Finnish Cultural Foundation and the South Ostrobothnia Regional Fund. The authors acknowledge Seinäjoki University of Applied Sciences for providing the research facilities for some of the analyses.

\section{References}

Abelenda, J.A., Navarro, C. \& Prat, S. 2014. Flowering and tuberization: A tale of two nightshades. Trends in Plant Science 19: 115-122. https://doi.org/10.1016/j.tplants.2013.09.010

Aisala, H., Manninen, H., Laaksonen, T., Linderborg, K.M., Myoda, T., Hopia, A. \& Sandell, M. 2020. Linking volatile and nonvolatile compounds to sensory profiles and consumer liking of wild edible Nordic mushrooms. Food Chemistry 304: 125403. https://doi.org/10.1016/j.foodchem.2019.125403

Aisala, H., Sinkkonen, J. Kalpio, M., Sandell, M., This, H. \& Hopia, A. 2016. In situ quantitative 1H nuclear magnetic resonance spectroscopy discriminates between raw and steam cooked potato strips based on their metabolites. Talanta 161: 245-252. https://doi.org/10.1016/j.talanta.2016.08.056

Becalski, A., Lau, B.P.-Y., Lewis, D., Seaman, S.W., Hayward, S. Sahagian, M., Ramesh, M. \& Leclerc, Y. 2004. Acrylamide in French fries: Influence of free amino acids and sugars. Journal of Agricultural and Food Chemistry 52: 3801-3806. https://doi.org/10.1021/jf0349376

Brierley, E.R., Bonner, P.L.R. \& Cobb, A.H. 1997. Aspects of amino acid metabolism in stored potato tubers (cv. Pentland dell). Plant Science 127: 17-24. https://doi.org/10.1016/S0168-9452(97)00109-X

Elmore, J.S., Mottram, D.S., Muttucumaru, N., Dodson, A.T., Parry, M.A.J. \& Halford, N.G. 2007. Changes in free amino acids and sugars in potatoes due to sulfate fertilization and the effect on acrylamide formation. Journal of Agricultural and Food Chemistry 55: 5363-5366. https://doi.org/10.1021/jf070447s

Eppendorfer, W.H. \& Bille, S.W. 1996. Free and total amino acid composition of edible parts of beans, kale, spinach, cauliflower and potatoes as influenced by nitrogen fertilisation and phosphorus and potassium deficiency. Journal of the Science of Food and Agriculture 71: 449-458. https://doi.org/10.1002/(SICI)1097-0010(199608)71:4<449::AID-JSFA601>3.0.CO;2-N

Ewing, E.E. \& Wareing, P.F. 1978. Shoot, Stolon and Tuber Formation on Potato (Solanum tuberosum L.) Cuttings in Response to Photoperiod. Plant Physiology 61: 348-353. https://doi.org/10.1104/pp.61.3.348

FAO 2021. FAOSTAT Database. Rome, Italy: FAO. http://www.fao.org/faostat/en/\#home. Accessed 15 June 2021.

Kirimura, J., Shimizu, A., Kimizuka, A., Ninomiya, T. \& Katsuya, N. 1969. The Contribution of Peptides and Amino Acids to the Taste of Foodstuffs. Journal of Agricultural and Food Chemistry 17: 689-695. https://doi.org/10.1021/jf60164a031

Hack, H., Gall, H., Klemke, T., Klose, R., Meier, U., Stauss, R. \& Witzenberger, A. 1993. The BBCH-scale for phonological growth stages of potato (Solanum tuberosum L.). Proceedings of the 12th Annual Congress of the European Association for Potato Research. Paris. p. 153-154.

Halford, N.G., Curtis, T.Y., Muttucumaru, N., Postles, J., Elmore, S.J. \& Mottram, D.S. 2012. The acrylamide problem: A plant and agronomic science issue. Journal of Experimental Botany 63: 2841-2851. https://doi.org/10.1093/jxb/ers011

Halpern, B.P. 2000. Glutamate and the flavor of foods. Journal of Nutrition 130: 921-926. https://doi.org/10.1093/jn/130.4.910S

Hårdh, K. \& Hårdh, J.E. 1977. Studies on quality of vegetable and strawberries at different latitudes in Finland. Annales Agriculturae Fenniae 16: 19-26.

Jackson, S.D. 2009. Plant responses to photoperiod. New Phytologist 181: 517-531.

https://doi.org/10.1111/j.1469-8137.2008.02681.x

Jansky, S.H. 2010. Potato flavor. American Journal of Potato Research 87: 209-217. https://doi.org/10.1007/s12230-010-9127-6

Järvi, A., Kangas, A., Mattila, I., Mäkelä, L., Rahkonen, A., Salo, Y., Vuorinen, M. \& Öfversten, J. 1998. Virallisten lajikekokeiden suoritusohjeet. Maatalouden tutkimuskeskuksen julkaisuja, sarja B 14. 71 p. (in Finnish).

Kirimura, J., Shimizu, A., Kimizuka, A., Ninomiya, T. \& Katsuya, N. 1969. The contribution of peptides and amino acids to the taste of foodstuffs. Journal of Agricultural and Food Chemistry 17: 689-695. https://doi.org/10.1021/jf60164a031

Kontukoski, M., Luomala, H., Mesz, B., Sigman, M., Trevisan, M., Rotola-Pukkila, M. \& Hopia, A.I. 2015. Sweet and sour: music and taste associations. Nutrition \& Food Science 45: 357-376. https://doi.org/10.1108/NFS-01-2015-0005

Kooman, P.L. \& Haverkort, A.J. 1995. Modelling development and growth of the potato crop influenced by temperature and daylength: LINTUL-POTATO. In: Haverkort, A.J. \& MacKerron, D.K.L. (eds.). Potato ecology and modelling of crops under conditions limiting growth. Proceedings of the Second International Potato Modeling Conference, held in Wageningen 17-19 May, 1994. https://doi.org/10.1007/978-94-011-0051-9_3 
Krauss, A. 1985. Interaction of nitrogen nutrition, phytohormones and tuberization. In: Li, P.H. (ed.). Potato Physiology. Academic Press, London. p. 209-231. https://doi.org/10.1016/B978-0-12-447660-8.50011-9

Marwaha, R.S. \& Sandhu, S.K. 2002. Yield, growth components and processing quality of potatoes as influenced by crop maturity under short and long days. Advances in Horticultural Science 16: 79-87. http://www.jstor.org/stable/42882196.

Mølmann, J.A.B., Fiskaa Hagen, S., Bengtsson, G.B. \& Johansen, T.J. 2018. Influence of high latitude light conditions on sensory quality and contents of health and sensory-related compounds in swede roots (Brassica napus L. ssp. rapifera Metzg.). Journal of the Science of Food and Agriculture 98: 1117-1123. https://doi.org/10.1002/jsfa.8562

Moorby, J. 1970 The production, storage, and translocation of carbohydrates in developing potato plants. Annals of Botany 34 : 297-308. https://doi.org/10.1093/oxfordjournals.aob.a084370

Morris, W.L., Ross, H.A., Ducreux, L.J.M., Bradshaw, J.E., Bryan, G.J. \& Taylor, M.A. 2007. Umami compounds are a determinant of the flavor of potato (Solanum tuberosum L.). Journal of Agricultural and Food Chemistry 55: 9627-9633. https://doi.org/10.1021/jf0717900

Oruna-Concha, M.J., Craig, D.S. \& Ames, J.M. 2001. Comparison of volatile compounds isolated from the skin and flesh of four potato cultivars after baking. Journal of Agricultural and Food Chemistry 49: 2414-2421. https://doi.org/10.1021/jf0012345

Paradiso, R., Arena, C., Youssef Rouphael, Y., d’Aquino, L., Makris, K., Vitaglione, P. \& De Pascale, S. 2019. Growth, photosynthetic activity and tuber quality of two potato cultivars in controlled environment as affected by light source. Plant Biosystems - An International Journal Dealing with all Aspects of Plant Biology 153:5: 725-735. https://doi.org/10.1080/11263504.2018.1549603

Ranogajec, A., Beluhan, S. \& Smit, Z. 2010. Analysis of nucleosides and monophosphate nucleotides from mushrooms with reversed-phase HPLC. Journal of Separation Science 33: 1024-1033. https://doi.org/10.1002/jssc.200900516

Rosen, C., Sun, N., Olsen, N., Thornton, M., Pavek, M., Knowles, L. \& Knowles, N.R. 2018. Impact of agronomic and storage practices on acrylamide in processed potatoes. American Journal of Potato Research 95: 319--327. https://doi.org/10.1007/s12230-018-9659-8

Rosenfeld, H.J., Risvik, E., Samuelsen, R.T. \& Rødbotten, M. 1997. Sensory profiling of carrots from northern latitudes. Food Research International 30: 593-601. https://doi.org/10.1016/S0963-9969(98)00027-1

Rotola-Pukkila, M.K., Pihlajaviita, S.T., Kaimainen, M.T. \& Hopia, A.I. 2015. Concentration of umami compounds in pork meat and cooking juice with different cooking times and temperatures. Journal of Food Science 80: C2711-C2716. https://doi.org/10.1111/1750-3841.13127

Rubio-Covarrubias, O.A., Douches, D.S., Hammerschmidt, R., daRocha, A. \& Kirk, W.W. 2006. Effect of photoperiod and temperature on resistance against Phytophthora infestans in susceptible and resistant potato cultivars: Effect on deposition of structural phenolics on the cell wall and resistance to penetration. American Journal of Potato Research 83: 325-334. https://doi.org/10.1007/BF02871593

Sato, H., Koizumi, R., Itoyama, R., Ichisawa, M., Negishi, J., Sakuma, R., Furusho, T., Sagane, Y. \& Takano, K. 2019. Free amino acids in potato (Solanum tuberosum) may cause egumi-taste in food products. Potato Research 62: 305-314. https://doi.org/10.1007/s11540-019-9412-9

Solms, J. \& Wyler, R. 1979. Taste components of potatoes. In: Food taste chemistry, ACS Symposium Series115: 175-184. American Chemical Society. https://doi.org/10.1021/bk-1979-0115.ch007

Steindal Hykkerud, A.L., Mølmann, J., Bengtsson, G.B. \& Johansen, T.J. 2013. Influence of day length and temperature on the content of health-related compounds in broccoli (Brassica oleracea L. var. italica). Journal of Agricultural and Food Chemistry 61 : 10779-10786. https://doi.org/10.1021/jf403466r

Stutte, G.W., Yorio, N.C. \& Wheeler, R.M. 1996. Interacting effects of photoperiod and photosynthetic photon flux on net carbon assimilation and starch accumulation in potato leaves. Journal of the American Society for Horticultural Science 121: 264-268. https://doi.org/10.21273/JASHS.121.2.264

Ulrich, D., Hoberg, E., Neugebauer, W., Tiemaim, H. \& Darsow, U. 2000. Investigation of the boiled potato flavor by human sensory and instrumental methods. American Journal of Potato Research 77: 111-117. https://doi.org/10.1007/BF02853738

Vivanti, V., Finotti, E. \& Friedman, M. 2006. Level of acrylamide precursors asparagine, fructose, glucose, and sucrose in potatoes sold at retail in Italy and in the United States. Journal of Food Science 71: C81-C85. https://doi.org/10.1111/j.1365-2621.2006.tb08886.x

Zheng, J., Kallio, H. \& Yang, B. 2009. Effects of latitude and weather conditions on sugars, fruit acids and ascorbic acid in currant (Ribes sp.) cultivars. Journal of the Science of Food and Agriculture 89: 2011-2023. https://doi.org/10.1002/jsfa.3682 